\title{
Clinicopathological and prognostic significance of Nanog expression in non-small cell lung cancer: a meta-analysis
}

This article was published in the following Dove Press journal: OncoTargets and Therapy

\author{
Guichuan Huang' \\ Jing Zhang ${ }^{2}$ \\ Xin Wang ${ }^{3}$ \\ Yi Chen ${ }^{3}$ \\ Daishun Liu' \\ Shuliang Guo ${ }^{3}$
}

'Department of Respiratory and Critical Care Medicine, The First People's Hospital of Zunyi, The Third Affiliated Hospital of Zunyi Medical University, Zunyi, Guizhou, People's Republic of China; ${ }^{2}$ Department of Respiratory and Critical Care Medicine, The First Affiliated Hospital of Zunyi Medical University, Zunyi, Guizhou, People's Republic of China; ${ }^{3}$ Department of Respiratory and Critical Care Medicine, The First Affiliated Hospital of Chongqing Medical University, Chongqing, People's Republic of China
Correspondence: Daishun Liu Department of Respiratory and Critical Care Medicine, The First People's Hospital of Zunyi, The Third Affiliated Hospital of

Zunyi Medical University, No 98 Fenghuang Road, Huichuan District, Zunyi, Guizhou, 563000 , People's Republic of China

Tel +86I 3885250001

Email IdsIwtg@|26.com

Shuliang Guo

Department of Respiratory and Critical Care Medicine, The First Affiliated Hospital of Chongqing Medical University, No I Youyi Road, Yuzhong District, Chongqing, 4000I6,

People's Republic of China

Tel +86I 3I0 I36 3078

Email guos1999@sina.com
Background: Nanog has been found to be overexpressed in various cancers. However, the association between Nanog expression and prognosis or clinicopathological features is still controversial. Therefore, this meta-analysis was conducted to identify whether Nanog expression was associated with prognosis or clinicopathological characteristics in nonsmall cell lung cancer (NSCLC).

Methods: We searched Embase, PubMed, Web of Science, the Cochrane Library, the Chinese National Knowledge Infrastructure database (CNKI), and the Wanfang database for articles. Pooled hazard ratios (HR), odds ratios (OR), and corresponding 95\% confidence intervals (CI) were utilized to evaluate the relationship between Nanog expression and prognosis or clinicopathological characteristics in NSCLC.

Results: The results showed that high expression of Nanog was significantly associated with poor overall survival (OS) $(\mathrm{HR}=1.95,95 \% \mathrm{CI}$ : 1.38-2.75, $P=0.000)$. Additionally, high Nanog expression was significantly correlated with tumor differentiation $(\mathrm{OR}=3.18,95 \%$ CI: $1.69-5.98, P=0.000)$ and TNM stage (OR=1.78, 95\% CI: $1.28-2.47, P=0.001)$. However, no significant relationship was observed between Nanog expression and other clinicopathological features, including gender $(\mathrm{OR}=0.95,95 \% \mathrm{CI}$ : $0.69-1.33, P=0.783)$, age $(\mathrm{OR}=0.78$, 95\% CI: $0.57-1.07, P=0.119)$, tumor size $(\mathrm{OR}=0.87,95 \% \mathrm{CI}: 0.26-2.95, P=0.824)$, and lymph node metastasis (OR=1.29, 95\% CI: $0.94-1.77, P=0.121)$.

Conclusion: High Nanog expression was associated with poor prognosis in patients with NSCLC, and Nanog may serve as a prognostic predictor in NSCLC.

Keywords: Nanog, NSCLC, meta-analysis

\section{Background}

Lung cancer is the leading cause of cancer incidence and mortality worldwide.

According to the guidelines of GLOBOCAN 2018, there will be an estimated 2.1 million new lung cancer cases and 1.8 million cancer deaths in 2018. ${ }^{1}$ Lung cancer can be divided into two major pathological subgroups: small cell lung cancer and non-small cell lung cancer (NSCLC). NSCLC accounts for $80 \sim 85 \%$ of all lung cancer cases, and contains three major histologic subtypes: adenocarcinoma, squamous cell carcinoma, and large-cell carcinoma. ${ }^{2}$ Although great advances have been made in the diagnosis of and treatment for NSCLC, the clinical outcomes still remain poor. Therefore, it is urgent that a specific therapeutic target and prognostic biomarker for NSCLC is discovered. 
Nanog is a homeobox domain transcription factor, and is a key regulator in embryonic development and cellular reprogramming. ${ }^{3}$ Nanog belongs to the NK-2 gene of the ANTP superfamily, in which the NK-2 gene is primarily expressed in the inner cell mass of blastocysts. ${ }^{4}$ Many studies have shown that Nanog is overexpressed in various cancers, including gastric cancer, ${ }^{5}$ breast cancer, ${ }^{6}$ ovarian cancer, ${ }^{7}$ liver cancer, ${ }^{8}$ and lung cancer. ${ }^{9} \mathrm{Li}$ et $\mathrm{al}^{10}$ found that increased Nanog expression was related to poor overall survival (OS) and differentiation of NSCLC. However, Gialmanidis et $\mathrm{al}^{11}$ reported that high Nanog expression had no association with differentiation, lymph node metastasis, and tumor clinical stage in NSCLC. Park et $\mathrm{al}^{12}$ found that Nanog expression was not related to prognosis in lung squamous cell carcinoma. Therefore, the association between Nanog expression and prognosis and clinicopathological features remains controversial. We conducted this metaanalysis to evaluate whether the expression of Nanog is related to prognosis and clinicopathological features in NSCLC patients.

\section{Material and methods}

\section{Literature search strategy}

This meta-analysis was conducted in compliance with the Preferred Reporting Items for Systematic Reviews and Meta-Analyses (PRISMA) statement. ${ }^{13}$ Embase, PubMed, Web of Science, the Cochrane Library database, the Chinese National Knowledge Infrastructure database (CNKI), and the Wanfang database were utilized for this meta-analysis. The keywords searched in the database were "Nanog or NANOG" and "lung cancer or lung neoplasm or lung carcinoma or lung tumor or pulmonary cancer." The search period ended on January 3, 2019. Titles and abstracts were assessed to identify the relevant literature, and then full texts were read.

\section{Inclusion and exclusion criteria}

Inclusion criteria for articles were as follows: (1) studies included were case-control studies (divided into either Nanog-positive and -negative groups or high and low Nanog expression groups) that evaluated the relationship between Nanog expression and prognosis or clinicopathological features in NSCLC; (2) sufficient data was provided for calculating HR, OR, and its corresponding $95 \%$ CI; (3) the number of NSCLC patients was greater than or equal to 30 ; (4) the expression of Nanog in NSCLC patients was detected by immunohistochemistry (IHC); (5) the full text was published in English or Chinese.

Exclusion criteria for the articles were as follows: (1) letters, reviews, conference abstracts, case reports, and expert opinions; (2) duplicate publications; (3) studies without available data.

\section{Data extraction and quality assessment}

All publications were screened independently by two reviewers (Guichuan Huang and Jing Zhang). The following information was extracted from eligible studies: the name of the primary author, year of publication, country, language, the number of patients, detection method, patient clinicopathological features, HR, and 95\% CI. The HR and corresponding $95 \%$ CI were directly or indirectly extracted from eligible studies according to the research of Tierney et $\mathrm{al}^{14}$. If both a multivariate analysis and univariate analysis were provided in the study, the data with multivariate analysis was adopted. If only Kaplan-Meier curves were provided, survival data was extracted using Engauge Digitizer software (Version 4.1). The quality of each study was evaluated with the use of the Newcastle-Ottawa Scale (NOS). Studies with a NOS score $\geq 6$ was considered to be of high quality. Any disagreements were resolved via discussion.

\section{Statistical analysis}

This meta-analysis was performed using Stata SE 12.0 software. For the data on overall survival, HR and its corresponding $95 \% \mathrm{CI}$ were applied to evaluate the strength of the relationship between Nanog expression and clinical prognosis in NSCLC patients. Pooled OR and corresponding 95\% CI were used for clinicopathological parameters. The chi-squared test and $I^{2}$ were used to evaluate the heterogeneity among the studies. A fixedeffect model was utilized if there was no obvious heterogeneity $\left(I^{2} \leq 50 \%\right.$ or $\left.P \geq 0.05\right)$. On the contrary, if $I^{2} \geq 50 \%$ or $P \leq 0.05$, a random-effect model was applied.

The publication bias was assessed with the use of Begg's test and Egger's test. A sensitivity analysis was also conducted to evaluate the stability of results. $P \leq 0.05$ was considered statistically significant.

\section{Results}

\section{Literature search and selection}

The literature selection process is demonstrated in Figure 1. We identified 776 articles from Embase, PubMed, Web of Science, the Cochrane Library, CNKI, and the Wanfang 


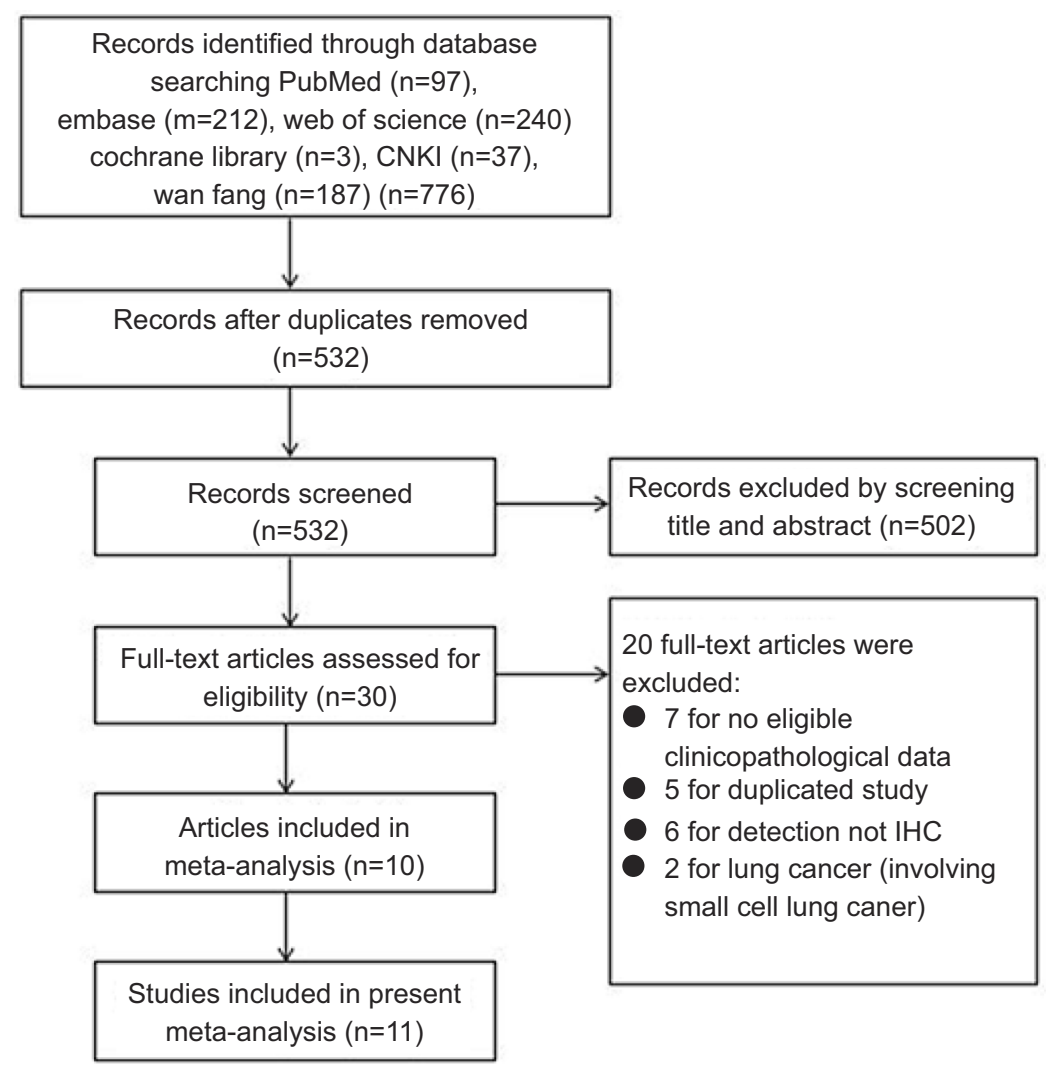

Figure I Flow chart of literature search and selection.

Abbreviations: CNKI, China National Knowledge Infrastructure; IHC, immunohistochemistry.

database. After the removal of duplicates, 532 potentially related articles remained. After 502 articles were excluded by screening their titles and abstracts, 30 articles remained for further full-text analysis. Finally, a total of 10 eligible studies that included 11 data sets with 1492 patients were included to conduct this meta-analysis. ${ }^{10-12,15-21}$

\section{Characteristics of included studies}

The characteristics of the included studies are listed in Table 1. These studies were published between 2010 and 2017. Of the 10 studies, 6 studies were conducted in China, 1 in Greece, 1 in Japan, and 2 in Korea. A total of 6 studies were published in English, and 4 studies were published in Chinese. The expression of Nanog was detected by IHC in all studies. The NOS scores of all included studies were greater than or equal to 6 , which implied that the studies were all of high quality.

\section{Association between nanog expression and OS}

A total of 5 articles that included 6 data sets with 963 patients reported the information on OS. As shown in
Figure 2, a random-effect model was used for the pooled HR and $95 \%$ CI due to heterogeneity $(P=0.034$, $\left.I^{2}=58.5 \%\right)$. The analysis indicated that high Nanog expression was related to poor OS in NSCLC patients $(\mathrm{HR}=1.95$, 95\% CI: $1.38-2.75, P<0.01)$. Furthermore, subgroup analyses were conducted according to publication year, sample size, and ethnicity to examine the sources of heterogeneity. As shown in Table 2, Nanog expression was associated with poor OS in the subgroup based on publication year, but heterogeneity was also found in these two subgroups. In the analysis stratified by sample size, Nanog expression was found to be significantly related to poor OS, and no heterogeneity was found in the subgroup with sample size $\leq 140 \quad(P=0.000, \mathrm{HR}=2.64,95 \% \mathrm{CI}$ : 1.94-3.60, $I^{2}=0 \%$ ). Interestingly, no association between Nanog expression and OS was found in the subgroup with sample size $>140(P=0.125, \mathrm{HR}=1.46,95 \%$ CI: $0.90-2.37$, $\left.I^{2}=55.3 \%\right)$. Likewise, there was no association between Nanog expression and OS in the subgroup of Korean ethnicity $(P=0.237, \quad \mathrm{HR}=1.61, \quad 95 \% \quad \mathrm{CI}: \quad 0.73-3.55$, $\left.I^{2}=78.9 \%\right)$. We then conducted a sensitivity analysis to ascertain the probable source of heterogeneity. We found that the heterogeneity significantly dropped $\left(I^{2}=37.7 \%\right.$, 


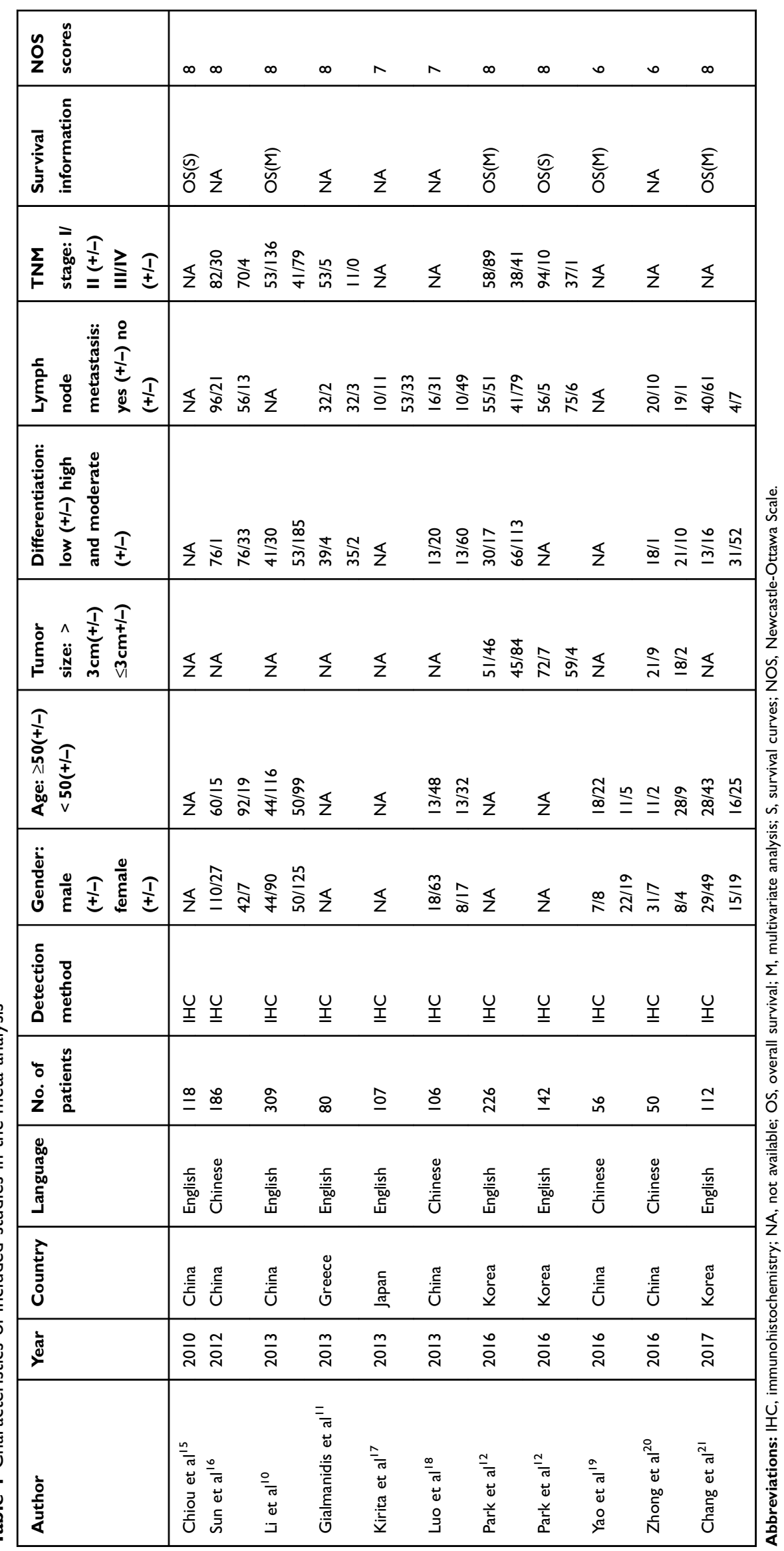




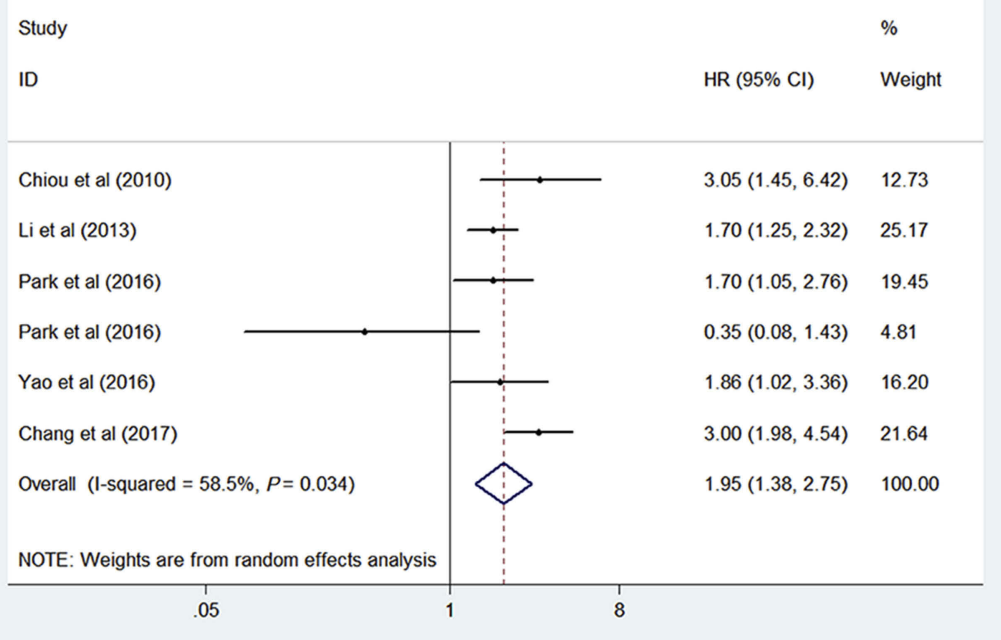

Figure 2 Forest plot for the association between Nanog expression and OS.

Abbreviation: OS, overall survival.

Table 2 Results of subgroup analysis of overall survival by publication year, sample size and ethnicity

\begin{tabular}{|c|c|c|c|c|c|c|}
\hline \multirow[t]{2}{*}{ Subgroup analysis } & \multirow[t]{2}{*}{ No. of studies } & \multirow[t]{2}{*}{ No. of patients } & \multirow[t]{2}{*}{$P$-value } & \multirow[t]{2}{*}{ HR (95\% Cl) } & \multicolumn{2}{|c|}{ Heterogeneity } \\
\hline & & & & & $I^{2}(\%)$ & $P$-value \\
\hline Total & 6 & 963 & 0.000 & $1.95(1.38-2.75)$ & 58.5 & 0.034 \\
\hline \multicolumn{7}{|l|}{ Publication year } \\
\hline$\leq 2013$ & 2 & 427 & 0.008 & $2.05(1.20-3.52)$ & 50.5 & 0.155 \\
\hline$>2013$ & 4 & 536 & 0.040 & $1.77(1.03-3.06)$ & 69.0 & 0.022 \\
\hline \multicolumn{7}{|l|}{ Sample size } \\
\hline$\leq 140$ & 3 & 286 & 0.000 & $2.64(1.94-3.60)$ & 0.0 & 0.399 \\
\hline$>140$ & 3 & 677 & 0.125 & $1.46(0.90-2.37)$ & 55.3 & 0.107 \\
\hline \multicolumn{7}{|l|}{ Ethnicity } \\
\hline Chinese & 3 & 483 & 0.000 & $1.86(|.43-2.4|)$ & I.I & 0.364 \\
\hline Korean & 3 & 480 & 0.237 & $1.61(0.73-3.55)$ & 78.9 & 0.009 \\
\hline
\end{tabular}

$P=0.170)$ without a change in pooled outcome $(\mathrm{HR}=2.09$, 95\% CI: 1.60-2.74) after excluding the Park study ${ }^{12}$ conducted on lung squamous cell carcinoma.

\section{Association between nanog expression and clinicopathological features}

The meta-analysis was performed to evaluate the association between Nanog expression and clinicopathological characteristics of NSCLC. As shown in both Figure 3 and Table 3, high Nanog expression was related to differentiation $(P=0.000$, $\mathrm{OR}=3.18,95 \%$ CI: $\left.1.69-5.98, I^{2}=62.5 \%\right)$ and TNM stage $\left(P=0.001, \quad\right.$ OR $=1.78, \quad 95 \% \quad$ CI: $\left.1.28-2.47, \quad I^{2}=49.0 \%\right)$. However, no significant relationship was observed between
Nanog expression and other clinicopathological features, including gender $(P=0.783, \mathrm{OR}=0.95,95 \%$ CI: $0.69-1.33$, $\left.I^{2}=0.0 \%\right)$ age $(P=0.119$, OR $=0.78,95 \%$ CI: $0.57-1.07$, $\left.I^{2}=0.0 \%\right)$, tumor size $(P=0.824, \quad \mathrm{OR}=0.87, \quad 95 \% \quad$ CI: $\left.0.26-2.95, I^{2}=71.9 \%\right)$, and lymph node metastasis $(P=0.121$, $\mathrm{OR}=1.29,95 \%$ CI: $0.94-1.77, I^{2}=49.4 \%$ ). Due to significant heterogeneity in tumor differentiation, the subgroup analysis of tumor differentiation was subsequently conducted via publication year, sample size, and ethnicity. As shown in Table 4, there was a significant relationship in the subgroup analysis of sample size between high Nanog expression and tumor differentiation in the large group $(\mathrm{n}>140)(\mathrm{OR}=5.08$, 95\% CI: $2.21-11.69, P=0.000)$, but not in the small group $(\mathrm{n} \leq 140) \quad(\mathrm{OR}=1.93,95 \%$ CI: $0.84-4.45, P=0.122)$. In the 
A

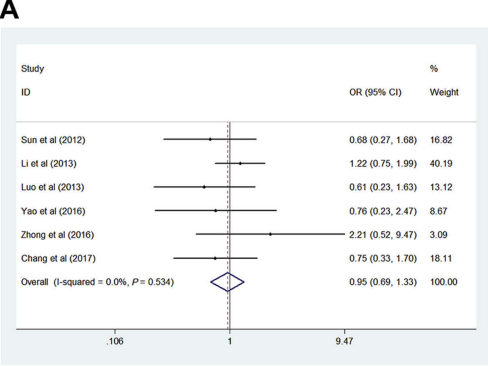

D

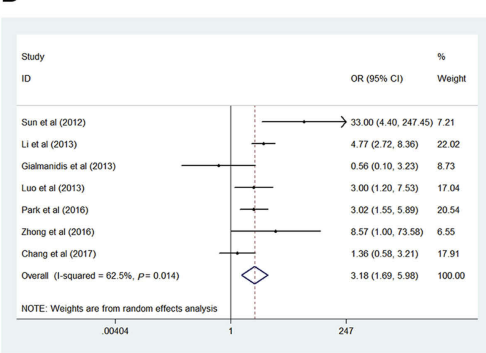

B

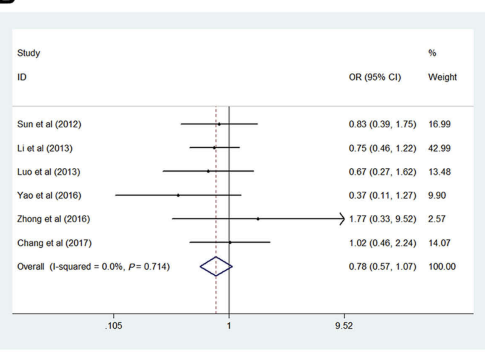

E

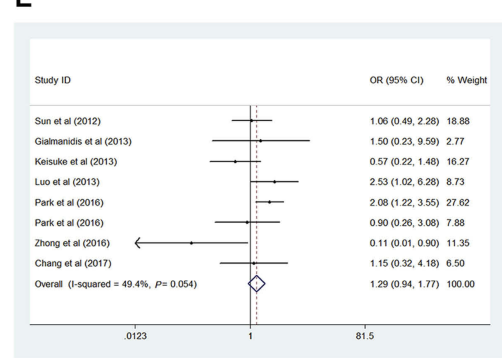

C

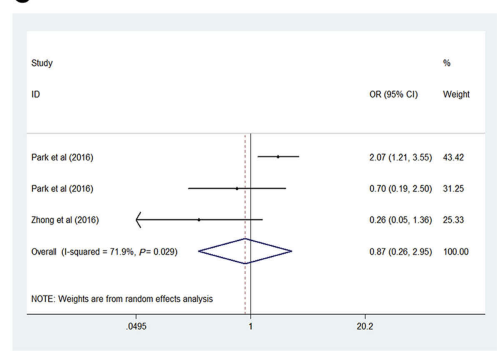

$\mathbf{F}$

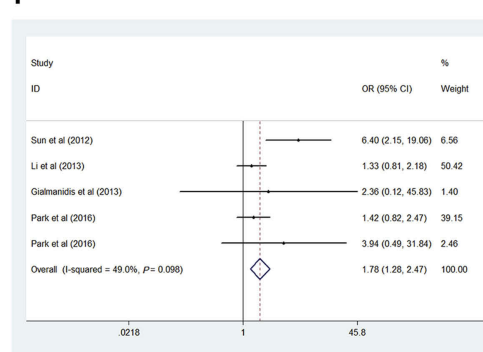

Figure 3 Forest plot for the association between Nanog expression and clinicopathological characteristics, including (A) gender, (B) age, (C) tumor size, (D) tumor differentiation, (E) lymph node metastasis, and (F) TNM stage.

Table 3 The association between Nanog expression and clinicopathological features

\begin{tabular}{|c|c|c|c|c|c|c|c|}
\hline \multirow[t]{2}{*}{ Clinicopathological features } & \multirow[t]{2}{*}{ No. of studies } & \multirow[t]{2}{*}{ No. of patients } & \multirow[t]{2}{*}{$P$-value } & \multirow[t]{2}{*}{ OR $(95 \% \mathrm{CI})$} & \multicolumn{2}{|c|}{ Heterogeneity } & \multirow[t]{2}{*}{ Model } \\
\hline & & & & & $I^{2}(\%)$ & $P$-value & \\
\hline Gender & 6 & 819 & 0.783 & $0.95(0.69-1.33)$ & 0.0 & 0.534 & Fixed \\
\hline Age & 6 & 819 & 0.119 & $0.78(0.57-1.07)$ & 0.0 & 0.714 & Fixed \\
\hline Tumor size & 3 & 418 & 0.824 & $0.87(0.26-2.95)$ & 71.9 & 0.029 & Random \\
\hline Differentiation & 7 & 1069 & 0.000 & $3.18(1.69-5.98)$ & 62.5 & 0.014 & Random \\
\hline LNM & 8 & 1009 & 0.121 & $1.29(0.94-1.77)$ & 49.4 & 0.054 & Fixed \\
\hline TNM stage & 5 & 943 & 0.001 & $1.78(1.28-2.47)$ & 49.0 & 0.098 & Fixed \\
\hline
\end{tabular}

Abbreviation: LNM, lymph node metastasis.

Table 4 Results of subgroup analysis of tumor differentiation by publication year, sample size and ethnicity

\begin{tabular}{|c|c|c|c|c|c|c|}
\hline \multirow[t]{2}{*}{ Subgroup analysis } & \multirow[t]{2}{*}{ No. of studies } & \multirow[t]{2}{*}{ No. of patients } & \multirow[t]{2}{*}{$P$-value } & \multirow[t]{2}{*}{ OR (95\% Cl) } & \multicolumn{2}{|c|}{ Heterogeneity } \\
\hline & & & & & $I^{2}(\%)$ & $P$-value \\
\hline Total & 7 & 1069 & 0.000 & $3.18(1.69-5.98)$ & 62.5 & 0.014 \\
\hline $\begin{array}{l}\text { Publication year } \\
\leq 2013 \\
>2013\end{array}$ & $\begin{array}{l}4 \\
3\end{array}$ & $\begin{array}{l}681 \\
388\end{array}$ & $\begin{array}{l}0.013 \\
0.021\end{array}$ & $\begin{array}{l}3.79(1.32-10.83) \\
2.47(1.15-5.32)\end{array}$ & $\begin{array}{l}70.7 \\
42.9\end{array}$ & $\begin{array}{l}0.017 \\
0.173\end{array}$ \\
\hline $\begin{array}{l}\text { Sample size } \\
\quad \leq 140 \\
>140\end{array}$ & $\begin{array}{l}4 \\
3\end{array}$ & $\begin{array}{l}348 \\
721\end{array}$ & $\begin{array}{l}0.122 \\
0.000\end{array}$ & $\begin{array}{l}1.93(0.84-4.45) \\
5.08(2.21-11.69)\end{array}$ & $\begin{array}{l}43.4 \\
64.5\end{array}$ & $\begin{array}{l}0.151 \\
0.060\end{array}$ \\
\hline $\begin{array}{l}\text { Ethnicity } \\
\text { Chinese } \\
\text { Korean + Greek }\end{array}$ & $\begin{array}{l}4 \\
3\end{array}$ & $\begin{array}{l}651 \\
418\end{array}$ & $\begin{array}{l}0.000 \\
0.214\end{array}$ & $\begin{array}{l}5.50(2.53-11.92) \\
1.69(0.74-3.86)\end{array}$ & $\begin{array}{l}44.9 \\
53.1\end{array}$ & $\begin{array}{l}0.142 \\
0.118\end{array}$ \\
\hline
\end{tabular}

subgroup analysis of ethnicity, high Nanog expression was associated with tumor differentiation for Chinese patients $(\mathrm{OR}=5.50,95 \%$ CI: 2.53-11.92, $P=0.000)$, but not for
Korean or Greek patients. Although subgroup analyses of tumor differentiation were conducted by publication year, sample size, and ethnicity, there still existed heterogeneity in 
every subgroup. The heterogeneity of Nanog expression and tumor differentiation, therefore, was not likely caused by publication year, sample size, or ethnicity. Because only three studies reported tumor size information, neither the subgroup analysis nor sensitivity analysis of tumor size were performed.

\section{Publication bias and sensitivity analysis}

We evaluated the publication bias in this meta-analysis via Begg's test and Egger's test. As shown in Table 5, there was no potential publication bias for OS, gender, age, tumor size, tumor differentiation, lymph node metastasis, or tumor TNM stage.

Sensitivity analysis was conducted to test whether a single study affected the pooled HR or OR. As shown in Figure 4, the pooled results were not influenced by removing individual studies.

\section{Discussion}

Many studies from the past several years have indicated that cancer stem-like cells (CSCs) play a crucial role in tumor development, progression, and metastasis. CSCs have been identified in many human cancer types, including hepatocellular carcinoma, ${ }^{22}$ bladder cancer, ${ }^{23}$ prostate cancer, ${ }^{24}$ breast cancer, ${ }^{25}$ and lung cancer. ${ }^{26}$ The identification and isolation of CSCs mainly depend on the use of surface markers which include CD44, CD90, CD13, SOX2, and OCT4. ${ }^{27}$ In recent years, Nanog was also identified as a surface marker of CSCs. ${ }^{28}$

Recently, many studies have indicated that Nanog expression is associated with various tumors. Liang et $\mathrm{al}^{29}$ found that Nanog expression was related to poor OS, tumor differentiation, and TNM stage in hepatocellular carcinoma. Likewise, Nanog expression was associated with the poor prognosis of gastrointestinal luminal cancer. ${ }^{30}$ Zhao et $\mathrm{al}^{31}$

Table 5 Publication bias evaluation by Begg's test and Egger's test

\begin{tabular}{|l|l|l|l|l|l|}
\hline Groups of outcomes & No. of studies & Estimates & Begg's test ( $P$-value) & Egger's test (P-value) & Publication bias \\
\hline OS & 6 & HR $+95 \% \mathrm{Cl}$ & 1.000 & 0.564 & Not significant \\
Gender & 6 & OR $+95 \% \mathrm{Cl}$ & 1.000 & 0.570 & Not significant \\
Age & 6 & OR $+95 \% \mathrm{Cl}$ & 1.000 & 0.873 & Not significant \\
Tumor size & 3 & OR $+95 \% \mathrm{Cl}$ & 0.296 & 0.079 & Not significant \\
Differentiation & 7 & OR $+95 \% \mathrm{Cl}$ & 0.764 & 0.939 & Not significant \\
LNM & 8 & OR $+95 \% \mathrm{Cl}$ & 0.462 & 0.232 & Not significant \\
TNM stage & 5 & OR $+95 \% \mathrm{Cl}$ & 0.462 & 0.240 & Not significant \\
\hline
\end{tabular}

Abbreviations: OS, overall survival; LNM, lymph node metastasis.
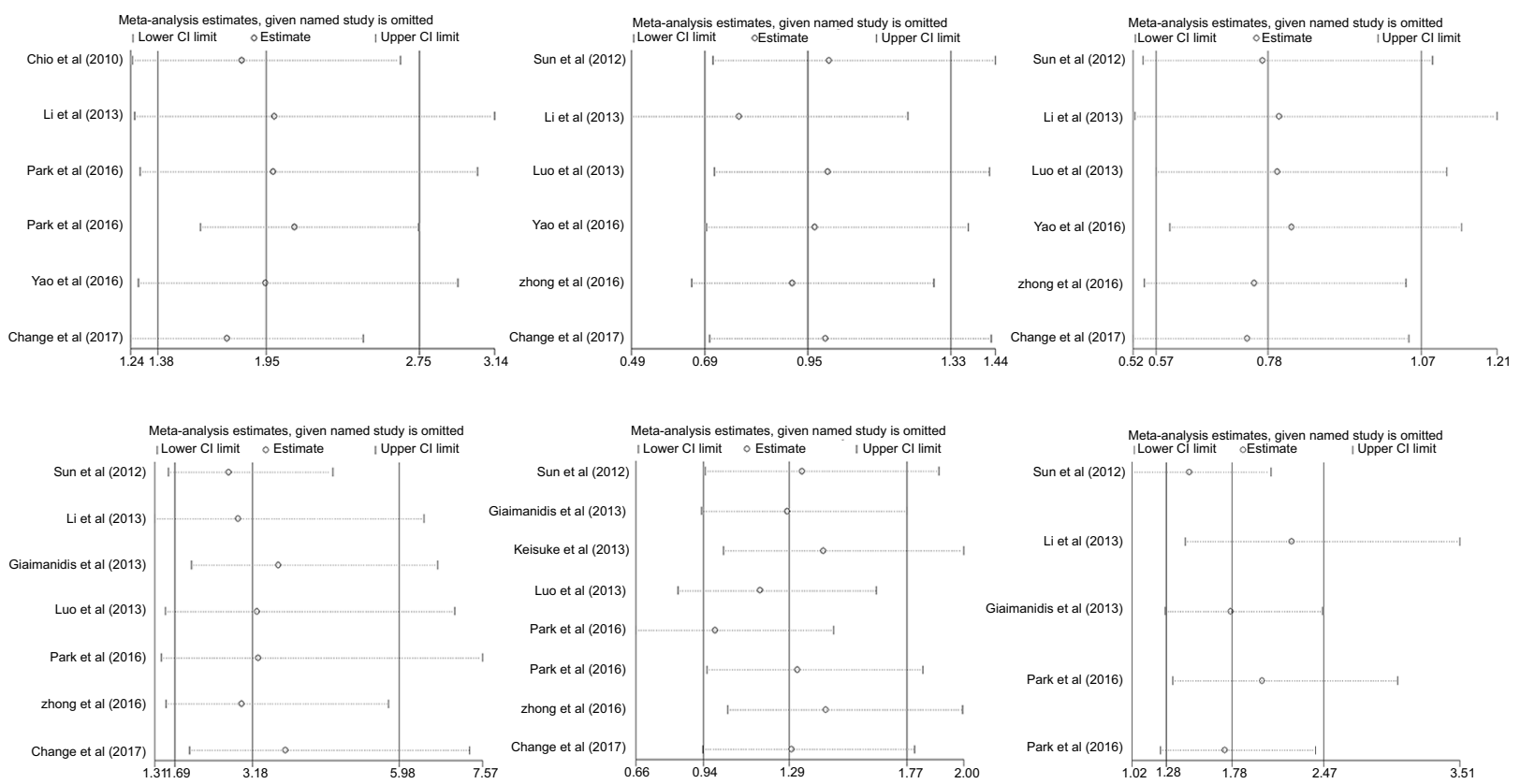

Figure 4 Sensitivity analysis for meta-analysis of (A) OS, (B) gender, (C) age, (D) tumor differentiation, (E) lymph node metastasis, and (F) TNM stage. 
found that high Nanog expression predicted a poor prognosis in solid tumors. However, the role of Nanog in NSCLC is still controversial, hence the performance of this meta-analysis. We believe that this meta-analysis is the first to identify the clinical significance of Nanog expression in NSCLC. A total of 10 studies containing 11 data sets with 1492 patients were included. The results indicated that high Nanog expression was related to poor OS, tumor differentiation, and tumor TNM stage in NSCLC, but not correlated with gender, age, tumor size, or lymph node metastasis. Cheng et $\mathrm{al}^{32}$ also found that the overexpression of Nanog was correlated with decreased OS and was related to tumor differentiation in lung cancer. Both of these findings were consistent with our results. However, Cheng et $\mathrm{al}^{32}$ also found that high Nanog expression was associated with tumor size and lymph node metastasis, which differed from our results. The following reasons may have led to this discrepancy. In Chen's metaanalysis, only 4 of the included studies for lymph node metastasis and 2 of the included studies for tumor size were combined in meta-analysis, which was less than the number of our included studies. Furthermore, the included studies in Chen's meta-analysis involved small cell lung cancer, which may also contribute to the difference in results.

In this meta-analysis, five of the six studies analyzed found that high Nanog expression was correlated with poor OS. Our pooled results also found that high Nanog expression was associated with poor OS. Additionally, sensitivity analysis was conducted to identify the source of heterogeneity for OS. We found that the heterogeneity significantly dropped $\left(I^{2}=37.7 \%, P=0.170\right)$ without a change in pooled analysis ( $\mathrm{HR}=2.09,95 \% \mathrm{CI}: 1.60-2.74)$ after excluding the Park study ${ }^{12}$ on lung squamous cell carcinoma. As is evident from these results, Nanog might be a potential prognostic biomarker in NSCLC. Of the seven studies, four studies indicated that Nanog expression was not associated with tumor differentiation. However, the pooled results indicated that Nanog expression was related to tumor differentiation. The reason for this result may be that Naong is a surface marker in cancer stem-like cells that can selfrenew and regulate differentiation. Similarly, four of the five studies demonstrated that high Nanog expression was not correlated with TNM stage. However, the pooled analysis indicated that high Nanog expression was related to advanced TNM stage. Park et $\mathrm{al}^{12}$ reported that Nanog expression was related to tumor size in lung adenocarcinoma but not in lung squamous cell carcinoma. Zhong et $\mathrm{al}^{20}$ declared that Nanog expression was not associated with tumor size in NSCLC. In the present meta-analysis, the combined results indicated that there was no statistical relationship between Nanog expression and tumor size. The reason for this may be that the sample size is small, and the histologic subtypes of NSCLC is not the same.

\section{Limitations}

There do exist some limitations of this study. First, HRs and their 95\% CIs were obtained from Kaplan-Meier survival curves instead of from the primary studies. Second, the cutoff value of positive or negative (high or low) Nanog expression is different in each study, which may cause heterogeneity. Third, moderate heterogeneity was found in the analysis of tumor size, tumor differentiation, and OS, which may influence the reliability of outcomes. Fourth, although no significant publication bias was found, the selection bias may exist in this retrospective meta-analysis. Finally, the number of included studies was relatively small. Therefore, additional high-quality and better-designed studies must be conducted to confirm our conclusion.

\section{Conclusion}

High Nanog expression was associated with poor prognosis in NSCLC patients, and Nanog may serve as a potential prognostic biomarker in NSCLC.

\section{Disclosure}

The authors report no conflicts of interest in this work.

\section{References}

1. Bray F, Ferlay J, Soerjomataram I, Siegel RL, Torre LA, Jemal A. Global cancer statistics 2018: GLOBOCAN estimates of incidence and mortality worldwide for 36 cancers in 185 countries. CA Cancer J Clin. 2018;68(6):394-424. doi:10.3322/caac.21492

2. Bareschino MA, Schettino C, Rossi A, et al. Treatment of advanced non small cell lung cancer. $J$ Thorac Dis. 2011;3(2):122-133. doi:10.3978/j.issn.2072-1439.2010.12.08

3. Jeter CR, Yang T, Wang J, Chao HP, Tang DG. Concise review: NANOG in cancer stem cells and tumor development: an update and outstanding questions. Stem Cells. 2015;33(8):2381-2390. doi: $10.1002 /$ stem. 2007

4. Do DV, Ueda J, Messerschmidt DM, et al. A genetic and developmental pathway from STAT3 to the OCT4-NANOG circuit is essential for maintenance of ICM lineages in vivo. Genes Dev. 2013;27 (12):1378-1390. doi:10.1101/gad.221176.113

5. Li N, Deng W, Ma J, et al. Prognostic evaluation of Nanog, Oct4, Sox2, PCNA, Ki67 and E-cadherin expression in gastric cancer. Med Oncol. 2015;32(1):433. doi:10.1007/s12032-014-0433-6

6. Jin C, Zhang X, Sun M, Zhang Y, Zhang G, Wang B. Clinical implications of the coexpression of SRC1 and NANOG in HER-2-overexpressing breast cancers. Onco Targets Ther. 2016;9:5483-5488. doi:10.2147/OTT.S102386 
7. Kenda Suster N, Frkovic Grazio S, Virant-Klun I, Verdenik I, Smrkolj S. Cancer stem cell-related marker NANOG expression in ovarian serous tumors: a clinicopathological study of 159 cases. Int J Gynecol Cancer. 2017;27(9):2006-2013. doi:10.1097/IGC.0000000000001105

8. Zhou JJ, Deng XG, He XY, et al. Knockdown of NANOG enhances chemosensitivity of liver cancer cells to doxorubicin by reducing MDR1 expression. Int J Oncol. 2014;44(6):2034-2040. doi:10.3892/ijo.2014.2347

9. Du YM, Ma C, Wang ZB, Liu ZL, Liu HF, Wang TY. Nanog, a novel prognostic marker for lung cancer. Surg Oncol. 2013;22(4):224-229. doi:10.1016/j.suronc.2013.08.001

10. Li XQ, Yang XL, Zhang G, et al. Nuclear $\beta$-catenin accumulation is associated with increased expression of Nanog protein and predicts poor prognosis of non-small cell lung cancer. J Transl Med. 2013;11 (1):114. doi:10.1186/1479-5876-11-114

11. Gialmanidis IP, Bravou V, Petrou I, et al. Expression of Bmi1, FoxF1, Nanog, and ${ }_{\gamma}$-catenin in relation to hedgehog signaling pathway in human non-small-cell lung cancer. Lung. 2013;191(5):511-521. doi:10.1007/s00408-013-9490-4

12. Park E, Park SY, Sun PL, et al. Prognostic significance of stem cell-related marker expression and its correlation with histologic subtypes in lung adenocarcinoma. Oncotarget. 2016;7(27):42502-42512. doi:10.18632/ oncotarget.9894

13. Moher D, Liberati A, Tetzlaff J, Altman DG. Preferred reporting items for systematic reviews and meta-analyses: the PRISMA statement. BMJ. 2009;339:b2535. doi:10.1136/bmj.b2651

14. Tierney JF, Stewart LA, Ghersi D, Burdett S, Sydes MR. Practical methods for incorporating summary time-to-event data into meta-analysis. Trials. 2007;8(1):16. doi:10.1186/1745-6215-8-16

15. Chiou SH, Wang ML, Chou YT, et al. Coexpression of Oct4 and Nanog enhances malignancy in lung adenocarcinoma by inducing cancer stem cell-like properties and epithelial-mesenchymal transdifferentiation. Cancer Res. 2010;70(24):10433-10444. doi:10.1158/0008-5472.CAN10-2638

16. Sun XD, Zong XF, Wang D. [Study on significance of expression of Nanog and Oct4 by using tissue chip technique in non-small cell lung cancer]. J Clin Expl Med. 2012;11(16):1258-1260. Chinese.

17. Kirita K, Ishii G, Matsuwaki R, et al. Identification of biological properties of intralymphatic tumor related to the development of lymph node metastasis in lung adenocarcinoma. PLoS One. 2013;8 (12):e83537. doi:10.1371/journal.pone.0083537

18. Luo MQ, Pu Q, Cao YL, et al. [Expression of Nanog in non-small cell lungcancer tissue]. J Zhengzhou Univ. 2013;48(6):758-761. Chinese.

19. Yao SM, He HY, Chen JL. [Correlations of Nanog expression in lung adenocarcinoma tissue with chemotherapy response and prognosis]. J Clin Res. 2016;33(12):2364-2367. Chinese.
20. Zhong CC [Expression and clinical significance of Nanog and Musashi1 in ES-NSCLC]. Thesis, Bengbu Medical College. 2016. Chinese.

21. Chang B, Park MJ, Choi SI, In KH, Kim CH, Lee SH. NANOG as an adverse predictive marker in advanced non-small cell lung cancer treated with platinum-based chemotherapy. Onco Targets Ther. 2017;10:4625-4633. doi:10.2147/OTT.S144895

22. Zheng H, Pomyen Y, Hernandez MO, et al. Single-cell analysis reveals cancer stem cell heterogeneity in hepatocellular carcinoma. Hepatology. 2018;68(1):127-140. doi:10.1002/hep.29778

23. Zhang Y, Wang Z, Yu J, et al. Cancer stem-like cells contribute to cisplatin resistance and progression in bladder cancer. Cancer Lett. 2012;322(1):70-77. doi:10.1016/j.canlet.2012.02.010

24. Patrawala L, Calhoun T, Schneider-Broussard R, et al. Highly purified CD44+ prostate cancer cells from xenograft human tumors are enriched in tumorigenic and metastatic progenitor cells. Oncogene. 2006;25(12):1696-1708. doi:10.1038/sj.onc.1209327

25. Ponti D, Costa A, Zaffaroni N, et al. Isolation and in vitro propagation of tumorigenic breast cancer cells with stem/progenitor cell properties. Cancer Res. 2005;65(13):5506-5511. doi:10.1158/00085472.CAN-05-0626

26. Eramo A, Lotti F, Sette G, et al. Identification and expansion of the tumorigenic lung cancer stem cell population. Cell Death Differ. 2008;15(3):504-514. doi:10.1038/sj.cdd.4402283

27. Martins-Neves SR, Cleton-Jansen AM, Gomes CMF. Therapyinduced enrichment of cancer stem-like cells in solid human tumors: where do we stand? Pharmacol Res. 2018;137:193-204. doi:10.1016/ j.phrs.2018.10.011

28. Noh KH, Kim BW, Song KH, et al. Nanog signaling in cancer promotes stem-like phenotype and immune evasion. J Clin Invest. 2012;122(11):4077-4093. doi:10.1172/JCI64057

29. Liang C, Zhang K, Ge H, Li W, Li G, Wu J. Prognostic and clinicopathological value of Nanog in hepatocellular carcinoma: A meta-analysis. Clin Chim Acta. 2018;477:24-31. doi:10.1016/j. cca.2017.11.037

30. Liang CJ, Zhao TJ, Ge H, et al. The clinicopathological and prognostic value of Nanog in human gastrointestinal luminal cancer: A meta-analysis. Int J Surg. 2018;53:193-200. doi:10.1016/j.ijsu.2018.03.050

31. Zhao L, Liu J, Chen S, Fang C, Zhang X, Luo Z. Prognostic significance of NANOG expression in solid tumors: a meta-analysis. Onco Targets Ther. 2018;11:5515-5526. doi:10.2147/OTT.S169593

32. Cheng W, Wang H, Yuan J, Cheng Z, Xing D, Zhang M. The prognostic value of Nanog overexpression in lung cancer: a meta-analysis. Biomed Res Int. 2018;2018:3429261. doi:10.1155/2018/3429261
OncoTargets and Therapy

\section{Publish your work in this journal}

OncoTargets and Therapy is an international, peer-reviewed, open access journal focusing on the pathological basis of all cancers, potential targets for therapy and treatment protocols employed to improve the management of cancer patients. The journal also focuses on the impact of management programs and new therapeutic

Submit your manuscript here: https://www.dovepress.com/oncotargets-and-therapy-journa agents and protocols on patient perspectives such as quality of life, adherence and satisfaction. The manuscript management system is completely online and includes a very quick and fair peer-review system, which is all easy to use. Visit http://www.dovepress.com/ testimonials.php to read real quotes from published authors. 